\title{
CAMINHOS DA PSICOLOGIA LATINO-AMERICANA COMO PRÁXIS DE LIBERTAÇÃO
}

\section{JOSÉ FERNANDO ANDRADE COSTA ${ }^{1}$ E CARLOS CÉSAR BARROS ${ }^{2}$}

RESUMO: O artigo trata do movimento de pensamento social crítico desenvolvido na América Latina na segunda metade do século XX, tomando como foco a chamada Psicologia da Libertação. São apresentadas as condições históricas e o contexto intelectual em que emerge a possibilidade de uma ciência psicológica contra-hegemônica e comprometida com os povos latino-americanos. Destaca-se o pensamento de Ignácio Martín-Baró, buscando estabelecer as bases para um diálogo interdisciplinar em torno da categoria "libertação". Por fim, são apresentados exemplos da psicologia crítica brasileira como práxis de libertação em diferentes contextos.

PALAVRAS-CHAVE: Libertação; América Latina; Psicologia.

ABSTRACT: This paper deals with the critical social thinking developed in Latin America in the second half of the twentieth century, focusing on the Liberation Psychology. The historical conditions and the intellectual context in which emerges the possibility of a non-hegemonic and committed psychology are presented. Ignacio Martín-Baró's thought is highlighted and we seek to lay the foundations for an interdisciplinary dialogue around "liberation". Finally, examples of Brazilian critical psychology are presented as forms of liberation praxis in different contexts.

KEYWORDS: Liberation; Latin America; Psychology.

Há cinco décadas surgiu um intenso debate em torno da possibilidade de se produzir um autêntico pensamento latino-americano. O pensador peruano Augusto Salazar Bondy (19251974) defendeu a tese de que nossa condição de subdesenvolvimento e alienação expressaria tais características também em nossa filosofia. Já o mexicano Leopoldo Zea (1912-2004) argumentou contra um universalismo abstrato e a favor da originalidade do pensamento latinoamericano, por compreender a filosofia como expressão de circunstâncias históricas concretas e defender a possibilidade de uma assimilação filosófica autêntica de pensamentos não latinoamericanos (CARVALHO, 2013). Ambos, contudo, compartilhavam um projeto comum em direção à autorreflexão sobre a dominação e a produção do filosofar original desde o "Sul Global" ou "periferia do capitalismo".

\footnotetext{
${ }^{1}$ Professor Assistente de Psicologia na Universidade Estadual de Feira de Santana (UEFS). Doutorando em Psicologia Social pelo Instituto de Psicologia da Universidade de São Paulo (IP-USP). E-mail: jfacosta@uefs.br.

${ }^{2}$ Professor Adjunto de Psicologia na Universidade Estadual de Feira de Santana (UEFS). Doutor em Psicologia Escolar e do Desenvolvimento Humano pela Universidade de São Paulo (USP). E-mail: carlosbarros@uefs.br.
} 
O contexto histórico do debate merece atenção. O recente desenvolvimento industrial num cenário populista com o varguismo ou o peronismo, por exemplo, entrava em contraste direto com o Cordobazo argentino e a Revolução cubana. Sob o clima da Guerra Fria e da doutrina da segurança nacional as ditaduras militares proliferavam e, à mão de ferro, buscavam controlar os ânimos "comunistas", desrespeitando acintosamente os direitos humanos. No campo teórico, o paradigma desenvolvimentista hegemônico começava a dar sinais de sua insuficiência enquanto crescia a reação crítica à condição de dependência econômica e cultural entre centro e periferia do capitalismo global. A realidade de desigualdade persistente e de violência política perpetrada pelas oligarquias locais a serviço dos interesses imperialistas resultou, como necessidade histórica, em um amplo movimento intelectual de contestação e de urgente chamado para ação e para a interpretação da realidade cotidiana de nossos povos. Esse amplo e difuso movimento adquiriu contornos mais explícitos na construção de uma autoimagem integrada da América Latina ao assumir como seu horizonte de realização histórica a tarefa de "libertação".

Em sua multiplicidade, esse movimento crítico reuniu distintas orientações teóricopráticas, desde tradicionais campos do saber - como a sociologia, teologia, filosofia, pedagogia e psicologia - até a formação de diversos grupos comunitários de luta por libertação nacional. Nesse contexto, a ideia de América Latina foi dialeticamente assimilada como um horizonte possível de transformação social e de autodeterminação dos povos historicamente oprimidos pelo poder hegemônico.

O processo de consolidação de uma "teoria latino-americana", como prefere FloresOsório (2009), ainda está em curso. Se, por um lado, há certa aproximação quanto à intenção crítica do pensamento latino-americano, por outro lado há também dissenso e efervescência em torno de temas como colonialidade, pós-colonialidade, anti-colonialidade e descolonialidade, entre outros. $\mathrm{O}$ debate permanece aberto e tem avançado neste início de século. Por isso, o diálogo entre distintos campos do saber é fundamental para o exercício do pensamento, especialmente entre filosofia e ciências empíricas, de modo que possamos caminhar em direção à construção de uma "teoria crítica latino-americana" como práxis de libertação.

Neste artigo abordaremos uma importante expressão desse contexto que se traduziu na proposta de ciência psicológica crítica e voltada para a libertação dos povos latino-americanos: a "Psicologia da Libertação" proposta por Ignácio Martín-Baró (1942-1989). Trata-se de uma vertente da psicologia para pensar e agir sobre a realidade concreta de nossos povos que tem sido cada vez mais assimilada em diversos países como alternativa ao reducionismo 
psicologista hegemônico (JIMÉNEZ-DOMÍNGUEZ, 2009). Buscamos aqui apresentar algumas de suas ideias por acreditarmos que o diálogo interdisciplinar em torno da categoria "libertação" pode ganhar muito com a proposta de uma ciência empírica e interventiva, como a psicologia. Além disso, compreender os mecanismos de conscientização ou reprodução ideológica da colonização, inclusive nas ciências ou no pensamento filosófico, é um problema central para o entendimento dos contextos atuais da América Latina.

O texto está estruturado em três partes, além desta introdução. No primeiro momento, iremos apresentar as condições históricas e o contexto intelectual no qual emerge um movimento de pensamento social crítico latino-americano que será fundamental para a construção de uma ciência psicológica contra-hegemônica e comprometida com as lutas dos povos oprimidos (I); em seguida, vamos dar ênfase ao pensamento do pioneiro e principal nome da Psicologia da Libertação latino-americana, Ignácio Martín-Baró, buscando estabelecer as bases para um diálogo interdisciplinar em torno da categoria "libertação" (II); por fim, recorreremos a exemplos da psicologia crítica brasileira como práxis de libertação em diferentes contextos (III). Esse exercício do pensamento não pretende esgotar as possibilidades de articulação entre filosofia e psicologia ou, mais especificamente, entre a teoria da libertação latino-americana e a práxis psicológica. Nosso intuito é, sobretudo, instigar a reflexão e convidar ao diálogo.

Tal como não é simples unificar a diversidade das histórias e contextos latinoamericanos, também é difícil descrever as diferentes filosofias, teologias e outras áreas que compõem o contexto de surgimento da Psicologia da Libertação. Os riscos reducionistas da ideologia da "raça latina" que herdamos do século XIX (MIGNOLO, 2005) encontram seus análogos na tentativa de unificação das filosofias da libertação em uma raiz ou origem comum (GULDBERG, 2014). Por isso, convém apresentar, brevemente, a complexidade do contexto histórico das filosofias da libertação, que também deu origem a campos como pedagogia, sociologia, antropologia ou teologia da libertação (FLORES-OSÓRIO, 2009). Apontaremos para algumas das principais influências da Psicologia da Libertação de Martín-Baró (1998), como uma preparação para a compreensão de algumas de suas principais ideias. Evidentemente, não se trata de esgotar as possibilidades de leitura sobre as origens e consequências epistemológicas da Psicologia da Libertação, pois este é um terreno fértil para desenvolver o 
pensamento crítico, como tem sido demonstrado por autores como Montero (2017) e Guzzo e Lacerda Júnior (2011).

A ideia de uma América "Latina" supõe a existência de uma característica comum - a latinidade - que a diferencia e opõe a uma América "Saxã". É estranho notar o poder homogeneizante dessa ideia perante a realidade de diferentes culturas e povos que habitam um mesmo continente. Esse é o resultado, segundo Walter Mignolo (2005), das transformações sócio-políticas ocorridas no período entre 1776 e 1830 quando se intensificaram os processos de disputa entre as elites crioulas e as nações colonizadoras europeias. A partir de meados do século XIX a ideia de um continente americano único passa a dar lugar à ideia de "duas" Américas, uma "saxã" e a outra "latina". Nesse processo é central a concepção de uma "raça latina" ou, ainda, a ideia mais difusa da "latinidade" ("latinidad”, "latinitée"), que surge como característica comum a portugueses, espanhóis e franceses. Essa ideia foi patrocinada pelo imperialismo francês como expressão de seu domínio na esfera cultural, em face ao domínio britânico sobre a esfera econômica. A força da ideologia da latinidade permitiria a formação de uma identidade nacional própria às ex-colônias, cujas elites crioulas começavam a projetar sua inserção na nova ordem capitalista como nações civilizadas. Assim, ao longo da segunda metade do século XIX, o termo "latina" passa de um adjetivo para um substantivo próprio que caracteriza todo um continente formado por diferentes nações - ainda que sem contornos bem definidos - as quais compartilhariam certos traços gerais em comum tais como a língua, a religião, a expressividade etc. A ideia de "América Latina" constituiu-se, então, como uma espécie de artefato político e cultural apropriado pelas elites locais ao longo do século XIX para afirmar uma imagem de si mesmas, em oposição aos Estados Unidos (América Saxã) que já começava a despontar no cenário internacional como um modelo de modernização.

Desde o início, a ideologia da modernização na América Latina se desenvolve sobre um terreno muito distinto daquele sobre o qual as nações europeias puderam erigir seus sistemas políticos e sociais sobre princípios universalistas de igualdade de direito. Aqui, a entrada para a modernidade ocorre pela assimilação dessas ideias ao mesmo tempo em que oculta a dominação permanente sobre povos indígenas e negros. Como aponta Mignolo,

Para conceberem a si mesmos como raça "Latina" (como diz Torres Caicedo), os crioulos na América "Latina" tiveram que rearticular a diferença colonial em um novo formato: tornaramse os colonizadores internos vis-à-vis indígenas e negros, enquanto vivem uma ilusão de independência da lógica da colonialidade. O colonialismo interno foi, de fato, uma marca registrada das Américas pós-independência e esteve diretamente ligado à construção dos Estados Nacionais (MIGNOLO, 2005, p. 86 tradução nossa). 
Como reflexo dessa assimilação ideológica dos ideais da Modernidade europeia, o grande desafio das nações latino-americanas permaneceu sendo como se civilizar a partir de formações societárias estruturalmente fraturadas e politicamente reativas a aspirações básicas de solidariedade. O caso do Brasil oitocentista é emblemático neste sentido - e Machado de Assis é um mestre na descrição de nossa incoerência -, quando as ideias liberais, de forma ornamental, conviviam entre as elites junto às práticas arraigadas de escravismo e favores (SCHWARZ, 2000). Mesmo com a abolição da escravatura e o advento da República, a sociedade brasileira não enfrentou sua própria história. Pelo contrário, a entrada para a modernidade foi capitaneada pelo racismo institucional e científico, a marginalização e criminalização da população negra e, principalmente, pela política de recebimento de grandes contingentes de imigrantes europeus para substituir a força de trabalho local e promover o embranquecimento da população. Esse padrão viria a ser tensionado pelas lutas sociais do início do século XX.

Há cerca de cem anos, o "mundo latino" viu lutas populares ampliarem os direitos das populações mais pobres com a Revolução Mexicana de 1917. Alguns anos mais tarde o varguismo deu origem a reformas sociais populistas sob regime ditatorial no Brasil, um processo semelhante ao do peronismo argentino. Após a Segunda Grande Guerra, os Estados Unidos lançaram sua Doutrina de Segurança Nacional, uma campanha anticomunista que muito influenciou os militares latino-americanos. Ainda assim, em 1959, efetivou-se a vitória da Revolução Cubana, anticapitalista e anti-americana. Esse clima de vitórias comunistas e de reação contra o "perigo vermelho" deu origem às diversas ditaduras militares no continente: Guatemala e Paraguai (1954), Argentina (1962), Brasil e Bolívia (1964), República Dominicana (1965), Peru (1968), Chile e Uruguai (1973), dentre outras. Lembremos que o país de origem da Psicologia da Libertação, El Salvador, teve governos militares praticamente durante o período aqui descrito.

Em 1948 foi criada pelo Conselho Econômico e Social das Nações Unidas a Comissão Econômica para a América Latina e o Caribe (CEPAL), que deu origem a análises sócioeconômicas que enfatizavam as desigualdades entre os povos latino-americanos e deram origem a uma colaboração intelectual entre os países do continente, mas ainda sob o paradigma desenvolvimentista. As teses cepalinas do desenvolvimento econômico autônomo foram criticadas na década de 1960 por uma nova teoria forjada no contexto dos golpes e ditaduras militares: a "teoria da dependência". Em suas diversas vertentes, esta corrente teórica enfatiza que os níveis de desenvolvimento econômico dos países capitalistas não devem ser 
interpretados de forma neutra, pois incluem relações sociais e políticas marcadas pela dominação nacional e transnacional. Nesse sentido, de certo modo, as vertentes dependentistas colocam a relação "centro" e "periferia" sob o enfoque da real possibilidade de soberania nacional dos países latino-americanos frente aos interesses dos Estados Unidos e dos países europeus centrais. De acordo com Ricúpero (2011), em torno desse debate surgiram novas críticas que avançam para além dos domínios tradicionais do economicismo. Essas críticas permitem operar certa "torção" daquilo que é importado dos centros para a periferia, revelando especificidades da dominação, uma vez que o modo de vida dos países centrais - sua economia, política e cultura - não constitui um padrão universal que deva ser assimilado naturalmente.

Assim, também no campo da educação emerge uma proposta de superação crítica do ensino hegemônico e reprodutivista do status quo. Essa crítica é materializada nos esforços de Paulo Freire em superar o tradicionalismo do que ele denomina "educação bancária" em direção a uma nova forma de educação como prática de liberdade, fundada pela conscientização e participação ativa no mundo. A essa proposta, Freire denomina "pedagogia do oprimido" (FREIRE, 1970/1987). Para ele, o educador deve reconhecer o educando como protagonista do processo de construção e apropriação cultural, numa transcendência da relação opressoroprimido. O mundo deve ser lido não para os sujeitos oprimidos, mas com eles. Trata-se de buscar a problematização da realidade para se conscientizar das amarras que impedem o desenvolvimento da vida em liberdade e comunhão. Nesta perspectiva, para agir no mundo, não basta apenas adquirir a capacidade técnica de decifrar os códigos linguísticos, mas é preciso ler o mundo; tampouco basta uma compreensão passiva da realidade, pois igualmente fundamental para uma educação libertadora é a capacidade de pronunciar o mundo. Assim, em relação dialógica, os oprimidos poderão libertar não apenas a si mesmos do jugo da opressão, mas também poderão libertar os opressores da dependência da dominação. A compreensão dos processos de colonização constrói uma consciência não apenas do passado e do presente, mas também do futuro, numa transformação mútua dos envolvidos no processo educacional com vistas à transformação da realidade.

No campo da sociologia, em suas vertentes críticas, a discussão em torno da construção do conhecimento buscava uma integração maior com a transformação social, dando origem às metodologias de pesquisa-ação participativa como forma de "sociologia da libertação" ou "militante" (FALS BORDA, 2014). Tratava-se de um compromisso com os oprimidos que via nas metodologias tradicionais um descompasso com a necessidade de transformação da realidade latino-americana. Para o colombiano Orlando Fals Borda, a sociologia militante deve 
determinar pontos de partida baseados nas condições concretas das pessoas, para depois chegar a estratégias transformadoras. Essa proposta possui as seguintes características: autenticidade e compromisso; antidogmatismo; devolução sistemática do conhecimento produzido nas pesquisas com as pessoas participantes; equilíbrio entre ação e reflexão; uma ciência modesta baseada em técnicas dialógicas e que valorize o conhecimento popular. Tal metodologia tornase fundamental para o desenvolvimento de diversas perspectivas críticas não apenas na sociologia, mas também para a Psicologia Social e Comunitária, uma vez que toma como critério para ação a necessidade de realizar um trabalho de pesquisa e intervenção de cunho interdisciplinar que não fique preso aos ditames do conhecimento hegemônico importado dos países do centro. Assim, a sociologia militante proposta por Fals Borda pressupõe a articulação entre produção de conhecimento e transformação da realidade como critério para a superação da apatia das análises sociológicas limitadas à denúncia do existente.

A força da crítica libertadora dos povos latino-americanos se manifestou também em setores tradicionais, como o cristianismo (LÖWY, 2016). Talvez a "teologia da libertação" seja uma das expressões mais conhecidas e difundidas desse amplo movimento de crítica social. Suas origens estão vinculadas à fundação do Conselho Episcopal Latino-Americano, em 1955, no Rio de Janeiro. Frente à condição dos oprimidos, considerada uma situação de pecado, o tema da transformação em Cristo ganhou uma interpretação de teor social, cujo fundamento soterológico encontra-se na libertação do povo escravizado. A libertação seria então um esforço de conversão radical, tal como a libertação do povo eleito, no Êxodo, ou a ressurreição de Cristo, no Evangelho. Atentos ao "sinal dos tempos", os teólogos da libertação propõem a "opção pelos pobres", que representam o sofrimento de Cristo sob a situação de opressão e injustiça. Os diversos movimentos internos à Igreja Católica na América Latina, no período das décadas de 1950 a 1970, fortaleceram a perspectiva de um chamado para ação eclesial como imperativo ético. Por isso, a difusão da perspectiva libertadora nas Comunidades Eclesiais de Base, espalhadas por diversos lugares onde o povo se encontra, favoreceu certas afinidades eletivas entre trabalho pastoral e ação social transformadora.

Nos círculos filosóficos, emergiu no final da década de 1960, na Argentina, um movimento de articulação da ideia de libertação em perspectiva filosófica. A "Filosofia da Libertação" começou a se desenvolver no início da década de 1970 também como resultado de um amplo movimento de assimilação das críticas produzidas na época. O mais importante representante da filosofia da libertação latino-americana é o pensador argentino Enrique Dussel, autor de vasta obra filosófica e de diálogos profícuos com grandes pensadores europeus, como 
Paul Ricoeur, Karl Otto-Apel, Charles Taylor e Richard Rorty (DUSSEL, 1995). A filosofia da libertação erige-se contra a epistemologia da Modernidade que reduz o "mundo" a determinados povos europeus. Essa filosofia critica a ontologia clássica que identifica o ser com o Ego europeu (eurocêntrico) e relega o Outro (latino-americano) à posição de não-ser, de bárbaro. Dussel busca desvelar como a experiência de dominação de um povo sobre outros se encontra subjacente ao pensamento moderno, pois "antes do ego cogito existe um ego conquiro (o ‘eu conquisto' é o fundamento prático do 'eu penso')” (DUSSEL, 1977/1996, p. 15, tradução nossa). Para Dussel (1995) a experiência inicial da filosofia da libertação consiste em descobrir o "fato" opressivo da dominação - a invasão europeia em 1492 -, pelo qual alguns sujeitos se constituem "senhores" de outros sujeitos. Essa descoberta deve cobrir o plano mundial (CentroPeriferia), o plano nacional (elites-massas, burguesia nacional-classe trabalhadora), o plano econômico (exploradores-explorados), o plano erótico (homem-mulher), o plano pedagógico (cultura imperial-cultura popular), o plano religioso etc.

Esta "experiência" inicial vivenciada por todo latino-americano, até mesmo nas aulas universitárias europeias de filosofia - se expressaria melhor dentro da categoria "Autrui" (outra pessoa tratada como outro), como pauper (pobre). O pobre, o dominado, o índio massacrado, o negro escravo, o asiático das guerras do ópio, o judeu nos campos de concentração, a mulher objeto sexual, a criança sujeita a manipulações ideológicas (também a juventude, a cultura popular e o mercado subjugados pela publicidade) não conseguirão tomar como ponto de partida pura e simplesmente, a estima de si mesmo. O oprimido, o torturado, o que vê destruída a sua carne sofredora, todos eles simplesmente gritam, clamando por justiça (DUSSEL, 1995, p. 19).

O grito é interpelação e, portanto, protopalavra que se encontra anterior ao estabelecimento da comunidade de comunicação ideal. Pois, assim como a selvageria do Caliban é primeiro atribuída ao fato de não saber falar a língua dos dominadores - mas que, uma vez aprendida, pelo menos lhe possibilita amaldiçoá-los (RICÚPERO, 2014, pp. 25-26) , também para a filosofia da libertação o pensamento europeu se impõe como um meio e não como um fim para a crítica da dominação. Para Dussel, é o sofrimento dos povos dominados que irá lançar um grito - um pranto, uma súplica - como "interpelação primitiva" clamando por reconhecimento e por justiça: “a 'responsabilidade' ou o 'assumir-o-outro' é anterior a qualquer consciência reflexa" (DUSSEL, 1995, p.19). Assim, a filosofia da libertação dusseliana se propõe a formular todo um sistema filosófico - desde uma nova metafísica a uma outra ontologia, partindo da alteridade absoluta do Outro - que seja tanto desvelador da realidade dos povos latino-americanos como também um projeto de emancipação a partir da práxis revolucionária libertadora.

Tal projeto, contudo, ainda está em desenvolvimento. Desde a formulação original a extensa obra de Dussel tem sido estudada principalmente em centros filosóficos latino- 
americanos de língua castelhana, mas relativamente com pouca presença tanto nas universidades brasileiras quanto nos países do Centro do capitalismo. E, quando transcende as fronteiras nacionais e linguísticas, ainda assim é difícil encontrar essas ideias ecoando para além dos círculos filosóficos. Mas há possibilidades de diálogo dessa filosofia com as ciências empíricas. Entendemos que, no campo da Psicologia, esse diálogo já conta com certo grau de desenvolvimento, porém ainda é necessário avançar no aprofundamento de seus pressupostos e implicações para diferentes âmbitos de atuação, considerando que a ciência psicológica se constitui por sua diversidade. Assim, passaremos agora a discutir como surgiu e tem se consolidado uma "Psicologia da Libertação" para, em um terceiro momento, discutir exemplos brasileiros de práxis psicológica libertadora.

A construção de uma Psicologia da Libertação exige uma libertação prévia da própria psicologia, isto é, uma libertação de sua dependência das teorias e modelos que atribuem universalidade ao sujeito "normal”, identificado com o europeu conquistador (nomeadamente: homem, branco, cisgênero, heterossexual, proprietário). Tal projeto requer, portanto, uma crítica radical à ciência psicológica e visa recuperá-la de sua cegueira epistêmica e prática, dotando-a de um sentido novo. O maior expoente desse projeto foi o psicólogo social, filósofo e sacerdote jesuíta Ignácio Martín-Baró, professor e vice-reitor na Universidade Centroamericana “José Simeón Cañas" (UCA), em El Salvador, até a madrugada de 16 de novembro de 1989, quando foi brutalmente assassinado dentro da UCA, junto a outras sete pessoas ${ }^{3}$, por um pelotão do exército salvadorenho treinado pelos EUA. Em seus trabalhos pioneiros - que aliam o interesse prático da pesquisa empírica com esforços sistemáticos de teorização Martín-Baró (1998) propôs uma radical mudança de rumo na construção da psicologia nos países latino-americanos, enfatizando a necessidade de priorizar uma leitura crítica da realidade dos povos oprimidos como base da atuação em psicologia.

De fato, a ciência psicológica na América Latina encontra-se, desde o início, submetida a uma relação de dependência servil aos modelos hegemônicos importados da Europa e dos

\footnotetext{
${ }^{3}$ Conhecidos como "Mártires da UCA", foram vitimados: Ignácio Ellacuría (reitor da UCA e Sacerdote Jesuíta); Segundo Montes (diretor do Instituto de Direitos Humanos da UCA e S. J.), Juan Ramón Moreno (diretor da biblioteca de Teologia e S. J.), Armando López (professor de Filosofia e S. J.), Joaquín López y López (membro fundador da UCA e S. J.), Elba Ramos (trabalhadora doméstica) e Celina Ramos (filha de Elba Ramos, menor de idade, e também trabalhadora doméstica).
} 
EUA, não apenas em relação à definição dos seus problemas e da busca das respectivas soluções, mas também no sentido de estar alheia aos movimentos e inquietudes dos povos latino-americanos. No entanto, será precisamente a partir da crítica ao caráter ideológico da psicologia hegemônica que poderá ser gestada uma psicologia como práxis libertadora. De forma esquemática, Martín-Baró apresenta três grandes problemas a serem enfrentados pela psicologia da libertação: o mimetismo cientificista, a ausência de uma epistemologia adequada para compreender a realidade latino-americana e a superação de falsos dilemas típicos do dogmatismo provinciano.

No primeiro caso, trata-se de abandonar a atenção que a psicologia tem dado a si mesma enquanto ciência positiva universal para dedicar-se, eficazmente, a compreender os problemas reais que afligem as maiorias populares. Isso significa colocar em questão a dependência de modelos teóricos importados, provenientes de realidades muito distintas, principalmente dos EUA, que são inadvertidamente tomados como cânones científicos. Como diz Baró, a aceitação acrítica de tais modelos é, precisamente, a negação dos fundamentos mesmos da ciência (MARTÍN-BARÓ, 1998, p. 289). Recusar o mimetismo cego é, portanto, assumir criticamente a responsabilidade da ciência perante a realidade concreta da qual é tributária. Se, por um lado, isso representa uma libertação da própria psicologia em relação às amarras do pensamento hegemônico mundial, por outro não significa ter que reinventar conceitos e sistemas teóricos desde o zero, mas apenas submetê-los todos ao exame crítico da realidade à qual se destinam.

Como decorrência desta crítica, no segundo problema é colocada em questão a ausência de uma epistemologia adequada. Na argumentação de Martín-Baró, isso significa problematizar certas orientações teórico-metodológicas que são tidas como pressupostos do fazer científico em psicologia, tais como o positivismo, o individualismo, o hedonismo, a visão homeostática e o a-historicismo. Do imperativo positivista atrelado ao fazer científico é questionada sua cegueira diante do princípio da negatividade, ou seja, a dependência do reducionismo e do controle leva ao idealismo metodológico que antepõe o marco teórico à realidade mesma, tornando opacas as contradições fundamentais que reproduzem a dominação social. Em relação ao individualismo, cada vez mais predominante na psicologia, Baró critica seu caráter ideológico na medida em que não apenas oculta a formação essencialmente social do indivíduo, como acaba reforçando as estruturas existentes ao reduzir questões de ordem estrutural a problemas pessoais. $\mathrm{O}$ hedonismo, por sua vez, reforça em todas as abordagens psicológicas o princípio do lucro fundante do sistema capitalista e, portanto, resulta em reificação da psicologia ao transpor para a esfera da natureza humana as características fundamentais de um 
sistema socioeconômico baseado na acumulação predatória. Também a tendência a certa visão homeostática dos processos psicológicos e das relações sociais é igualmente ideológica na medida em que faz apologia da ordem existente e condena ao status de desequilíbrio ou patologia qualquer expressão destoante da norma social vigente. Por fim, o pressuposto epistemológico mais grave da psicologia é a consideração a-histórica da natureza humana, pois leva à obliteração das diferenças em favor de certo universalismo abstrato.

Em terceiro lugar encontra-se a dependência provinciana da psicologia a falsos dilemas, como, por exemplo, a existência de uma "psicologia reacionária", de um lado, e uma "psicologia revolucionária", de outro. Não se trata de reproduzir polarizações partidárias no interior da psicologia, fragmentando-a em distintos setores a partir de adjetivos tais como "científica", "humanista", "materialista" etc. Esse é um falso problema, pois o que irá tornar uma determinada teoria válida e relevante, ou não, será sua capacidade para explicar ou ocultar a realidade e, sobretudo, para transformar ou apenas reforçar a ordem social. A postura crítica é, portanto, antidogmática. Seu compromisso é a busca da verdade sobre a realidade dos povos latino-americanos e, como consequência, da busca de meios de transformação das situações de opressão. É por isso que o projeto de psicologia da libertação não se reduz a uma subdisciplina da psicologia, tal como a psicologia escolar, do trabalho ou comunitária. Antes, a ideia de "libertação" é mais profunda e se dirige a um horizonte social que ao mesmo tempo engloba e transcende os limites da psicologia enquanto disciplina e práxis.

Martín-Baró propõe, então, uma radical redefinição da bagagem teórica e prática da psicologia conhecida até então, tendo como fundamento máximo a concretude da vida dos nossos próprios povos, seus sofrimentos, aspirações e suas lutas. Para elaborar uma Psicologia da libertação, novamente Martín-Baró (1998) esquematiza três caminhos: será necessário estabelecer um novo horizonte para a psicologia, construir uma nova epistemologia e buscar uma nova práxis. Em primeiro lugar, será necessário estabelecer a libertação dos povos latinoamericanos como horizonte da práxis psicológica, o que exige tanto a redefinição dos modelos teóricos-metodológicos quanto o trabalho pelo fortalecimento das ações populares de resistência à dominação. Isso implica perseguir um novo objetivo para a psicologia nos processos de mudança pessoal e social, qual seja, o compromisso de colocar seu trabalho a serviço da catalisação de processos de transformação da realidade desencadeados pelo e para o povo. Como decorrência desse novo horizonte prático, em segundo lugar, será necessário construir uma nova epistemologia. Esta deverá partir desde os "de baixo" da estrutura social, os marginalizados e oprimidos de todos os matizes que anseiam por libertação para viver a vida 
em plenitude. Embebida na experiência de resistência do povo oprimido e animada por suas esperanças e desejos de um futuro melhor, a psicologia da libertação poderá encontrar uma nova matriz sobre a qual desenvolver seus conceitos e técnicas. Não se trata, obviamente, de descartar os conhecimentos já existentes, mas de revisá-los criticamente à luz da realidade das maiorias populares. Somente assim a psicologia poderá provar seu real alcance e utilidade. Por fim, para construir um novo conhecimento não basta apenas buscar conhecer a perspectiva do povo, mas é necessário assumir uma nova práxis, uma atividade transformadora da realidade que permita conhecê-la não apenas no que é, mas também naquilo que ainda não é, ou seja, a partir da orientação para a exigência do devir histórico em uma perspectiva libertadora. MartínBaró defende, com isso, um realismo crítico no qual a realidade concreta tem primazia sobre o conhecimento que temos dela e faz eco à tese de que para melhor conhecê-la, temos que transformá-la.

Metodologicamente, as proposições de Martín-Baró (1998) para uma nova psicologia, elaborada desde e para a América Latina, foram influenciadas tanto pela perspectiva dialógica da pedagogia do oprimido de Paulo Freire, quanto pela pesquisa-ação participante da sociologia militante de Orlando Fals Borda. Sua atuação como psicólogo social junto às populações vulneráveis em El Salvador, durante período de sangrenta guerra civil, possibilitou aprofundar a análise de conceitos como "fatalismo", "poder" e "identidade social". Além disso, a obra de Martín-Baró consolidou a perspectiva de uma psicologia orientada para a conscientização, desideologização e desnaturalização de processos sociais de dominação visando articular a crítica decolonial à práxis libertadora.

Após a trágica morte de Martín-Baró, em 1989, seguiu-se um período de relativa latência no desenvolvimento da Psicologia da libertação até 1998, quando foi realizada a primeira Conferência Internacional de Psicologia da Libertação, no México. A partir daí esse modo de pensar e fazer psicologia difundiu-se não apenas por toda América Latina e outros países da Periferia do capitalismo, mas também em países do Centro, como EUA, Inglaterra e Austrália, entre outros. No Brasil, atualmente, o legado de Martín-Baró tem se consolidado a partir de alguns centros de pesquisa em psicologia crítica e de traduções publicadas recentemente (MARTÍN-BARÓ, 2017). Desse modo, quanto mais acessíveis e discutidas forem essas ideias, mais longe chegará seu alcance e potencial transformador. É inevitável, evidentemente, que surjam leituras distintas e inclusive divergentes sobre aspectos teóricos da obra de Martín-Baró, mas isso está longe de significar um problema, uma vez que o princípio máximo sobre o qual será possível construir uma psicologia da libertação diz respeito à crítica radical da realidade 
concreta de injustiça e opressão vivida pelas maiorias populares. As questões teóricas acerca da centralidade metodológica do materialismo histórico-dialético, do pragmatismo estadunidense, da eclesiologia católica, entre outras questões, são certamente pertinentes, mas secundárias. Por outro lado, há de fato um risco de cristalização da obra de Martín-Baró como pertencente exclusivamente ao campo da Psicologia Social ou da Psicologia Política. Esse risco é compreensível na medida em que cada vez mais a avaliação sobre a produção acadêmica pressiona por especialismos ao invés de atuações integradas e, também, o neocolonialismo epistêmico ganha espaço na formulação de currículos de cursos de graduação e pós-graduação voltados apenas para o mercado.

A Psicologia da libertação permanece sendo, desde suas origens, uma psicologia essencialmente contra-hegemônica, como o é, por definição, todo pensamento crítico. Propomos, então, realizar agora uma leitura panorâmica de produções da psicologia brasileira que já há algum tempo têm sido exemplos da intencionalidade crítica da psicologia da libertação latino-americana, ainda que não necessariamente nomeadas de tal forma. Essa leitura, ainda que limitada, nos permite pensar o resgate da ideia de libertação de modo original, não apenas como um processo incipiente e orientado exclusivamente por uma literatura única, mas como um processo histórico mais amplo que encontra-se em andamento, tem produzido resultados positivos e pode ser analisado como síntese, em diversas frentes, dos anseios básicos da proposta de Martín-Baró, ainda que sob uma pluralidade de referências e âmbitos de ação.

No Handbook of Critical Psychology, Raquel Guzzo argumenta que a psicologia crítica na América Latina, ainda que com dificuldades, tem se constituído como "um movimento para mudança social que visa acabar com a opressão que afeta os mais pobres, excluídos e explorados, e visa o empoderamento de indivíduos e grupos, bem como o aumento da participação social e política nos espaços comunitários" (GUZZO, 2015, p. 413, tradução nossa). Essa consideração decorre da análise das transformações ocorridas na ciência psicológica latino-americana, desde os primeiros referenciais acriticamente importados dos países centrais em meados do século XX até as produções contestatórias gestadas no interior de diversas abordagens psicológicas nas últimas décadas. Os desafios permanecem, mas é possível vislumbrar e estabelecer um novo momento de reflexões sobre a orientação teórico-prática da psicologia em nosso continente. No último passo deste texto, vamos apresentar um breve 
panorama do quadro atual. Não pretendemos esgotar o debate, mas oferecer um mosaico de possibilidades críticas da psicologia atual, mesmo que isso signifique deixar abertas muitas lacunas.

A principal vertente da psicologia a lidar com o problema da colonização do pensamento, desde o início, foi a psicologia social. Não por acaso, em muitos fóruns internacionais a psicologia da libertação de Martín-Baró tem sido denominada "psicologia social da libertação". Ainda que seja um equívoco reduzir a perspectiva da libertação à psicologia social, é compreensível essa associação. De fato, a psicologia social latinoamericana, desde a década de 1970, se caracteriza pela forte presença da noção de "crítica". Essa crítica origina-se da contestação da insuficiência dos modelos hegemônicos importados que não eram suficientes para dar respostas aos problemas concretos vividos pelas maiorias populares em nosso continente. No Brasil, uma importante representante dessa virada crítica foi a filósofa e psicóloga social, Silvia Lane. Ao redor do seu grupo de pesquisa na Pontifícia Universidade Católica de São Paulo, Silvia Lane estabeleceu as bases de uma psicologia social crítica fundamentada no materialismo histórico dialético, cujos resultados são notados não apenas nos estudos sobre diversos temas - tais como ideologia, consciência, atividade, identidade, emoções, linguagem, processo grupal etc. -, mas também na formação de uma geração de pesquisadores/as, com nomes como Bader Sawaia, Fátima Quintal de Freitas, Ana Bock, Antônio Ciampa, Marcos Vieira Silva, entre muitos outros. A respeito dessa produção, Lane e Sawaia afirmam que

Nossa trajetória não é solitária. Descobrimos que nossas preocupações afligem muitos psicólogos sociais da América Latina que conosco partilham o paradoxo do contemporâneo. (...) É preciso conhecer quem é o homem que se constitui nas condições sócio-históricas da América Latina. (...) E, sem dúvida, a contribuição de Ignácio Martín-Baró foi de suma importância. Suas obras e sua presença na Sociedade Interamericana de Psicologia marcaram-nos a todos, preocupados com um saber científico voltado para as questões cruciais de nossos países (LANE \& SAWAIA, 2006, p. 8)

De forma semelhante à psicologia social, também no campo da psicologia política latino-americana ocorre uma espécie de "giro" ao continente latino-americano nas últimas décadas. A psicologia política nasce e se desenvolve como campo específico da ciência psicológica nos Estados Unidos, no início do século $\mathrm{XX}$, ainda que suas raízes remetam à filosofia política moderna. No entanto, seu significado passa por intensas disputas na América Latina. Martín-Baró é, mais uma vez, personagem importante nesse cenário na medida em que sua proposta de psicologia da libertação foi antes denominada tanto "psicologia popular" como "psicologia política". Esta última, na perspectiva latino-americana, tem sido, em geral, uma "psicologia política politizada", o que não necessariamente ocorre com sua homônima 
estadunidense. Trata-se de um campo com grande vitalidade, que tem produzido diversos estudos, nos mais variados âmbitos da ação humana, interessados nos fenômenos psicopolíticos, isto é, naquele ponto de intersecção entre o psicológico e o político. Uma síntese do estado atual da psicologia política latino-americana, também denominada "psicologia política crítica", foi apresentada por Hur e Lacerda Júnior, quando afirmam:

Grande parte dos pesquisadores direciona-se à Psicologia Política por um compromisso ético, político e militante com os grupos sociais que são historicamente esmagados na América Latina, seja por questões financeiras, sociais, étnico-culturais, de raça, gênero, orientação sexual etc. A maioria das pesquisas vem assumindo uma implicação política por aquele que é explorado e oprimido, tentando impulsionar uma potencialização dos movimentos e da organização desses coletivos sociais, tendo como horizonte a autonomia e a emancipação. (...) Portanto, a Psicologia Política latino-americana tem como grito de guerra o "Ya Basta" zapatista. Já basta de nos mantermos calados e submetidos à lógica da exploração que vigora neste continente por mais de cinco séculos. (...) Com isso queremos expressar como nossa produção e campo acadêmico, explicitamente, assumem sua faceta política e de luta pela dignidade e defesa dos que são diariamente massacrados e oprimidos. Somos herdeiros dessa tradição crítica e de combate e, por isso, temos o compromisso ético-político de prosseguir com essas lutas e reflexões (HUR, \& LACERDA JÚNIOR, 2016, pp. 8-9)

A intencionalidade revolucionária da psicologia política crítica é, de certa forma, tributária daquela vertente que talvez seja a mais fortemente orientada para a prática transformadora da realidade entre todas as formas de psicologia: a psicologia comunitária. Assim como a psicologia social e a psicologia política, também a psicologia comunitária desenvolvida na América Latina distingue-se daquela que emerge nos Estados Unidos, na década de 1960. Mas, enquanto campo de produção teórica e prática, a psicologia comunitária latino-americana orienta-se, desde o início, para a transformação das condições de vida das comunidades oprimidas. O fato de a psicologia comunitária em nosso continente ter se desenvolvido junto às lutas das comunidades populares talvez explique o porquê de raramente encontrarmos o qualificativo "crítica" a ela associado, provavelmente por este ser-lhe um pressuposto. Trata-se de uma psicologia que decorre da práxis. Como observam Maritza Montero e Irma Serrano-García (2011), em uma obra que reúne a trajetória da psicologia comunitária em vinte países latino-americanos, há uma tradição de trabalhos comunitários se consolidando em nosso continente. Não obstante a diversidade característica de nossos povos, são muitos os pontos de coincidência entre praticantes da psicologia comunitária latinoamericana, principalmente em relação aos aspectos éticos, políticos e participativos do fazer comunitário.

Somos agentes de mudança social (facilitadores/as, interventores/as, investigadores/as), com um compromisso político e ético com os necessitados/as que nos leva a tomar partido, a ser críticos/as, a fomentar a desideologização e a conscientização da opressão e da injustiça. Utilizamos ferramentas conceituais e aplicadas de nossa disciplina e de outras para facilitar a participação cidadã, a autogestão e o fortalecimento das comunidades na esperança de que 
eventualmente não mais nos necessitem (MONTERO \& SERRANO-GARCÍA, 2011, p.37, tradução nossa).

Atualmente a psicologia comunitária se configura como um respeitado campo de pesquisa e prática. Seu objeto e âmbito de atuação são as comunidades e as relações que nelas se estabelecem; os métodos podem ser os mais variados, mas geralmente busca-se o princípio participativo e interventivo, destacando-se a pesquisa-ação participante. Diversos conceitos orientam a prática psicossocial comunitária, tais como: fortalecimento comunitário ("empoderamento", potenciação); participação e compromisso; consciência, habituação, familiarização, naturalização e ideologia; conscientização, problematização e desideologização; emoções e afetividade; entre outros.

Mas não é apenas no âmbito social-político-comunitário que vislumbramos os caminhos da psicologia para uma práxis libertadora. Também em espaços mais tradicionais, como a psicologia escolar, há contribuições críticas significativas. O trabalho de Maria Helena de Souza Patto, pelo menos desde sua tese de doutorado de 1981, publicada em 1984 como o livro Psicologia e ideologia: uma introdução crítica à Psicologia Escolar, tem muitas aproximações com a proposta libertadora e vem influenciando todo um campo de produção denominado "Psicologia Escolar Crítica". A indignação com a exclusão escolar de boa parcela da população pobre brasileira, ou com o fracasso escolar, expresso na reprovação ou na evasão, conduziu à denúncia da hegemonia de uma visão de mundo. Compreender o fracasso escolar não como uma patologia individual da criança que não aprende, mas como um processo histórico complexo, conduz à denúncia da Psicologia como ideologia reducionista e psicologizante. Patto (1984) lança mão da teoria da dependência, da pedagogia do oprimido e da sociologia da educação para denunciar a docilização dos corpos e a violência simbólica, a partir de um minucioso estudo da história do Brasil e da educação brasileira. A partir desse "banho de realidade" brasileira, a psicologia escolar crítica está ciente e denuncia o caráter ideológico da ciência em geral, mais especificamente da pretensa ciência psicológica que no contexto brasileiro foi construída num campo discriminatório composto pelas teorias racistas, pela psicometria e pela teoria da carência cultural. Se as escolas ensinam as crianças a obedecer e a não se expressar, a Psicologia tem atuado na transformação das histórias de rebeldia (desobediência e expressão criativa) em uma série de patologizações medicalizantes. A colonização também acontece entre as diferentes classes sociais dentro de um país. Patto (1984) lança mão de uma forte expressão sartreana, inspirada em Frantz Fanon, a "mordaça sonora" que se instaura no fracasso escolar ou na patologização psicológica das classes oprimidas. A 
perspectiva crítica em psicologia escolar e educacional se propõe a desideologizar a psicologia para que esta possa transformar os caminhos educacionais na direção da mudança social.

Outra direção, neste mesmo sentido, é tomada pela ampla gama de práticas que podem ser reunidas em torno da "luta antimanicomial". Nesse caso, o lugar tradicional da psicologia como difusora do saber produzido pela psiquiatria e psicopatologia encontra uma via de expressão crítica, pois toma como ponto de partida a experiência concreta dos sujeitos e grupos que sofrem não apenas com um diagnóstico de transtorno mental, mas também com o estigma, abandono e exclusão social. A figura do "louco" é profundamente criticada - não apenas na América Latina - desde a segunda metade do século XX. Em nosso continente, e mais especificamente no Brasil, temos observado a formação de uma parcela significativa de psicólogos/as comprometidos/as com um fazer profissional colocado a serviço da vida, da construção de uma rede de atenção psicossocial baseada na redução de danos, na promoção da cidadania e na oposição à lógica das instituições manicomiais. A libertação, nesse sentido, transcende a esfera pública na medida em que a afirmação radical da liberdade de agir no mundo exige também o cuidado pessoal com a saúde mental e a garantia do desenvolvimento das capacidades e desejos individuais como fundamento do respeito à dignidade humana.

De modo semelhante, no âmbito das relações de trabalho há um desenvolvimento da ciência psicológica que não adere ao discurso da organização capitalista e aos interesses da reprodução do Capital. Ao lado da psicologia organizacional há uma psicologia do trabalho que, mesmo com dificuldades, consegue contribuir para a construção de um horizonte libertador na medida em que recupera o sentido ontológico do trabalho e das relações cotidianas de afirmação da vida. Os trabalhos de Leny Sato são exemplos do engajamento da psicologia com o mundo do trabalho desde a perspectiva concreta do cotidiano de vida dos/as trabalhadores/as. Em sua tese de livre-docência, Sato (2012) investigou a "feira livre" para, a partir dela, pensar a relação entre trabalho e sociabilidade de forma crítica.

A cooperação simples associada à bricolagem abre espaço para que os feirantes planejem, inventem e criem incessantemente. O feirante não é um operário de uma empresa centralmente administrada, mas também não é um trabalhador que tem aberto um espaço infinito de autonomia. Entre um polo e outro, lançando mão de táticas e estratégias, a sobrevivência é garantida diariamente: têm-se que "matar um leão por dia". (...) Arte, cultura e comicidade são fortes feições desse espaço de sociabilidade e de trabalho. (...) Estudar a feira livre é também estudar o chão de fábrica rotinizado pelo inverso. Inverso que também permite conhecer traços comuns entre ambos quando se toma o chão do cotidiano por referência. No trabalho rotinizado, redes de relações, cooperação e competição e acordos válidos apenas entre vizinhos também são construídos; as dimensões estética e cômica encontram nichos menos evidentes para expressão, mas estão presentes. Micronegociações e "jeitinhos" acontecem. No entanto, no caso da feira livre, essas características dão-se à luz do dia não sendo necessário arrancá-las por debaixo de prescrições estritas (SATO, 2012, pp. 225-227). 
Essa perspectiva sensível e atenta ao cotidiano, isto é, àquilo que se passa quando aparentemente nada se passa, permite refletir sobre o alcance da libertação para além das lutas sociais mais evidentes. Há um espaço de ação que não deixa de ser político, mas que não é transparente a determinadas lentes de análise. Essa contribuição retira sua força, em grande medida, da análise sócio-técnica das relações de trabalho, tomando o cotidiano como objeto privilegiado de uma verdadeira "ciência do detalhe".

Além desses âmbitos mais tradicionais - saúde mental, educação e trabalho - a práxis libertadora da psicologia torna-se mais explícita nas produções mais recentes. É expressão disso o crescente número de psicólogos/as que tematizam relações étnico-raciais desde a perspectiva libertadora - recorrendo às contribuições de autores/as como Frantz Fanon, Neusa Souza, Maria Aparecida Bento, Alessandro de Oliveira dos Santos, entre outros - e estabelecendo um vigoroso debate acadêmico e político em torno dos problemas associados aos efeitos psicossociais do racismo estrutural, da branquitude, da colonização epistêmica, da necropolítica etc.

Também encontramos a perspectiva libertadora nos estudos críticos sobre gênero, sexualidade e diversidade sexual. Mesmo sob ataques dos setores conservadores que visam limitar a reflexão e ação nesse campo, a produção acadêmica em psicologia tem sido atenta à realidade de movimentos sociais, coletivos, grupos e indivíduos que levantam pautas identitárias e lutam por reconhecimento. Temas como feminismos, masculinidades, identidades de gênero, orientação sexual, performatividade, entre outros, são objeto da práxis libertadora da psicologia tanto em termos de produção de conhecimento crítico quanto em termos de orientação para ação e desenvolvimento de estratégias de cuidado e promoção de saúde e bem estar.

Quando pensamos nessa miríade de possibilidades de atuação da psicologia como práxis libertadora, é necessário incluir também a noção de territorialidade, pois cada sujeito age no mundo a partir de um lugar. Por isso, cada vez mais o território tem sido objeto de estudo e intervenção para as vertentes críticas da psicologia. Aldeias indígenas, comunidades quilombolas, contextos rurais e periferias urbanas, de modo geral, são exemplos da necessidade de construção de uma psicologia contra-hegemônica e libertadora territorialmente referenciada, pois raramente encontramos essas realidades tematizadas nos livros-textos básicos da formação. Mudar esse estado de coisas é uma tarefa urgente e que já se encontra em andamento. Mas isso tem sido igualmente desafiador, na medida em que a produção acadêmica atual tem sido balizada por critérios de produtividade que tendem a favorecer a ultraespecialização e deixam 
pouco espaço para assumir a perspectiva intereseccional. No entanto, esse espaço é criado nas brechas e interstícios da academia. E, como tal, é locus de resistência e de oportunidade para o surgimento do novo.

Por fim, para encerrar esse breve sobrevoo de possibilidades da psicologia como práxis de libertação, consideramos fundamental assumir a defesa intransigente dos Direitos Humanos. Atentos à Declaração Universal dos Direitos Humanos, consideramos "que o reconhecimento da dignidade inerente a todos os membros da família humana e de seus direitos iguais e inalienáveis é o fundamento da liberdade, da justiça e da paz no mundo" (ONU, 1948/2013, p. 246, grifo nosso). O termo "reconhecimento", para além do senso comum, pode ser lido como fundamento de uma crítica social de base intersubjetiva, assim como o conceito de "dignidade" deve ser assumido como uma conquista histórica da humanidade capaz de orientar os anseios de luta por libertação de toda situação de opressão. Podemos dizer que, se, por um lado, a perspectiva da psicologia como práxis de libertação colabora para os objetivos de defesa dos direitos humanos, por outro, a linguagem dos direitos humanos permite situar o horizonte da libertação como uma contribuição para além das fronteiras de um continente específico. Com isso, coloca-se o desafio de recuperar o elo perdido, na esfera do pensamento, entre libertação e emancipação humana; entre a crítica da dominação e a superação das situações de opressão. Essa é uma contribuição que, pela práxis, a psicologia talvez possa oferecer ao pensamento latino-americano.

\section{REFERÊNCIAS BIBLIOGRÁFICAS}

CARVALHO, E. R. A polêmica entre Leopoldo Zea e Augusto Salazar Bondy sobre a existência de uma filosofia americana (1968-1969). In: Ideias, Campinas, v.4, n. 2, 2013, pp. 181-202. DOI: https://doi.org/10.20396/ideias.v4i2.8649389

DUSSEL, E. Filosofia da libertação: crítica da ideologia da exclusão. São Paulo: Paulus, 1995.

DUSSEL, E. Filosofía de la liberación. Bogotá: Editorial Nueva America, 1996. Publicado originalmente em 1977.

FALS BORDA, O. ¿Es posible una sociología de la liberación? In: FARFÁN, Nicolás A. H. \& GUZMÁN, Lorena L. (eds.). Ciencia, compromiso y cambio social. Textos de Orlando Fals Borda. Montevideo: El Colectivo - Lanzas y Letras - Extensión Libros, 2014, pp. 149-154.

FLORES-OSÓRIO, J. M. Praxis and Liberation in Context of Latin American Theory. In: MONTERO, Maritza. \& SONN, Christopher. (eds.) Psychology of Liberation: theory and applications. Springer, 2009, pp. 11-36. DOI: 10.1007/978-0-387-85784-8

FREIRE, P. Pedagogia do oprimido. 17a ed. Rio de Janeiro: Editora Paz \& Terra, 1987. Publicado originalmente em 1970.

GULDBERG, H.C. Filosofía de la liberación latinoamericana. Primera edicción eletcrónica. México: Fundo de Cultura Econômica, 2014. 
GUZZO, R. S. L. Critical psychology and the American continent: from colonization and domination to liberation and emancipation. In: PARKER, Ian. (ed.) Handbook of Critical Psychology. New York: Routledge, 2015, pp. 406-414.

GUZZO, R.S.L. \& LACERDA JÚNIOR, F. Sobre o sentido e a necessidade do resgate crítico da obra de Martín-Baró. In: GUZZO, R.S.L.; LACERDA JÚNIOR, F. (Orgs.). Psicologia social para América Latina: o resgate da psicologia da libertação. 2. ed. Campinas, SP: Editora Alínea, 2011.

HUR, D. \& LACERDA JÚNIOR, F. (eds.) Psicologia política crítica: insurgências na América Latina. Campinas: Editora Alínea, 2016.

JIMÉNEZ-DOMÍNGUEZ, B. Ignacio Martín-Baró's Social Psychology of Liberation: situated knowledge and critical commitment against objectivism. In: MONTERO, Maritza. \& SONN, Christopher. (eds.) Psychology of Liberation: theory and applications. Springer, 2009, pp. 3750. DOI: $10.1007 / 978-0-387-85784-8$

LANE, S. T. M. \& SAWAIA, B. B. (eds.) Novas veredas da Psicologia Social. São Paulo: Editora Brasiliense-Educ, 2006.

LÖWY, M. O que é cristianismo da libertação? Religião e política na América Latina. In: São Paulo: Editora Fundação Perseu Abramo - Expressão Popular, 2016.

MARTÍN-BARÓ, I. Psicología de la liberación. Edição, introdução e notas de Amálio Blanco. Epílogo de Noam Chomsky. Madrid: Editorial Trotta, 1998.

MARTÍN-BARÓ, I. Crítica e libertação na psicologia: estudos psicossociais. Organização, notas e tradução de Fernando Lacerda Júnior. Petrópolis, RJ: Editora Vozes, 2017.

MIGNOLO, W. The Idea of Latin America. Malden: Blackwell Pub, 2005.

MONTERO, M. Psychology of Liberation Revised (A Critique of Critique). In: GOUGH, Brendan (ed.) The Palgrave Handbook of Critical Social Psychology. Leeds, UK: Palgrave Macmillan, 2017, pp. 147-161.

MONTERO, M. \& SERRANO-GARCÍA, I. (eds.) Historias de la psicología comunitaria en América Latina: participación y transformación. Buenos Aires: Paidós, 2011.

ONU. ORGANIZAÇAO DAS NAÇÕES UNIDAS. Declaração Universal dos Direitos Humanos. In: COMPARATO, F.K. A afirmação histórica dos direitos humanos. 8.ed. São Paulo: Saraiva, 2013. p. 246-252. Texto publicado originalmente em 1948.

PATTO, M. H. S. Psicologia e ideologia. Uma introdução crítica à psicologia escolar. São Paulo: Editora T. A. Queiroz, 1984.

RICÚPERO, B. O lugar do centro e da periferia. In: BOTELHO, André. \& SCHWARCZ, Lilia M. (orgs.) Agenda brasileira: temas de uma sociedade em mudança. São Paulo: Companhia das Letras, 2011, pp. 92-101.

RICÚPERO, B. A Tempestade e a América. In: Lua Nova - Revista de cultura e política, n. 93, set./dez., 2014, pp. 25-26. DOI: 10.1590/S0102-64452014000300002

SATO, L. Feira livre: organização, trabalho e sociabilidade. São Paulo: Edusp, 2012.

SCHWARZ, R. Ao vencedor as batatas. São Paulo: Duas Cidades/Editora 34, 2000. 